\title{
INFILTRAÇÃO POLICIAL: A LINHA TÊNUE ENTRE A LEGALIDADE E A ILEGALIDADE
}

Barbara Candido de Araujo

Universidade do Oeste Paulista - UNOESTE. Curso de Direito, Presidente Prudente- SP. E-mail: barbaracandido7@outlook.com

\section{RESUMO}

A infiltração policial como meio de prova, apesar de contemplada em lei ordinária e na Convenção de Palermo, a qual fora ratificada pelo Brasil, ainda não alcançou a efetividade que, provavelmente, os legisladores esperavam. Dentre os motivos que justificam seu desuso está a obscuridade do tema tanto no que se refere ao conhecimento público do instituto, quanto aos resultados prejudiciais que poderão surgir no decorrer da investigação. Destarte, buscar-se-á comparar e demonstrar o posicionamento preponderante quando há colisão entre os direitos fundamentais, ademais, serão demonstrados os limitadores daquilo que o agente público faz no desempenho de suas funções. Por fim, conclui-se com uma visão panorâmica da infiltração policial, demarcando sua extensão, objetivos e requisitos, focando na ambiguidade da defesa social contraposta aos direitos individuais.

Palavras-chave: Infiltração policial; meios probatórios; constitucionalidade; direitos fundamentais; organizações criminosas.

\section{POLICE INFILTRATION: THE FINE LINE BETWEEN LEGAL AND ILLEGAL}

\begin{abstract}
Police infiltration as evidence, although contemplated in ordinary law and the Palermo Convention, which was ratified by Brazil, has not yet reached the effectiveness likely, legislators expected. Among the reasons for its lack of use is the subject of so much obscurity in respect to public awareness of the institute as the damaging results that may arise in the course of the investigation. Thus, it will be sought to compare and demonstrate the leading position when there is collision between fundamental rights, moreover, the constraints of what the public official does in the performance of its functions will be demonstrated. Finally, we conclude with an overview of police infiltration, marking its extent, objectives and requirements, focusing on the ambiguity of social defense as opposed to individual rights.
\end{abstract}

Keywords: Police infiltration; evidentiary means; constitutionality; fundamental rights; criminal organizations. 


\section{INTRODUÇÃO}

No Brasil, a legislação prevê que "ninguém poderá alegar a própria torpeza para se defender", por óbvio, conclui-se através da afirmação, que todos os habitantes deste país, devem conhecer tudo aquilo que a lei dispõe.

Devido a grandeza do ordenamento e as diferenças sociais que permeiam a nação, o desejo do legislador, anteriormente descrito, figura como utopia.

Diante disto, objetivando colaborar com a popularização do tema e de suas consequências, que podem restar, inclusive, na preponderância de determinados direitos fundamentais quando em oposição aos outros, o trabalho aborda de forma simplista o assunto, fixando um paralelo entre o Poder-dever de punir do Estado e as garantias individuais.

Ademais, são trazidos os requisitos para a habilitação do agente infiltrado e para a utilização do instituto que apesar de previsto legalmente desde 1995, ainda parece história de ficção dos filmes norte americanos.

\section{METODOLOGIA}

$O$ instituto da infiltração policial fora analisado através de pesquisa bibliográfica exploratória, sendo assim, objetiva-se com o presente trabalho inteirar o leitor sobre este instrumento jurídico.

\section{RESULTADOS}

A análise pretende estender os conhecimentos teóricos obtidos em sala de aula, trazendo a discussão hipótese, em regra, desconhecida pelo "homem médio brasileiro".

Portanto, visando contextualizar parcela da população, ainda que restrita, que terá acesso a este escrito ou assistirá a apresentação do mesmo e fomentar o autoconhecimento pátrio: foram compiladas as informações que seguem.

\section{DISCUSSÃO}

\section{EVOLUÇÃO HISTÓRICA DO INSTITUTO}

Por ter sido o Código de Processo Penal publicado na década de 1940, no Título VII, que concerne às provas, não há referência à infiltração policial, sendo dispostos como instrumentos probatórios apenas o exame de corpo de delito, as perícias, o interrogatório do acusado, a confissão, os depoimentos da vítima e das testemunhas, o reconhecimento de pessoas e coisas, a acareação, os documentos, os indícios e a busca e apreensão.

Porém com a evolução social, fruto do capitalismo e da globalização, os meios de prova outrora previstos se tornaram antiquados frente às novas formas de cometimento de ilícitos. Do mesmo modo que as instituições públicas e privadas se organizaram, passando a atuar em diversos países e até continentes, o crime também se especializou.

A organização criminosa, ainda que precariamente abordada, já despontava como fato típico na jurisdição brasileira em 1995 e era exemplo, desta estruturação negativa, principalmente no que tange ao tráfico de drogas. Para combater tais infortúnios e influenciado por tendências europeias, o legislador também precisou inovar nas formas de investigação, valendo-se para tanto, do mesmo diploma legal.

No Brasil, inicialmente, a infiltração como instrumento processual penal foi trazida pela antiga lei das Organizações Criminosas, ou seja, a Lei 9.034 de 03 de maio 1.995, em seu artigo 2응 inciso $\mathrm{V}$, a qual cerca de dezoito anos depois foi revogada pela Lei 12.850 . Aquela dispunha:

Em qualquer fase de persecução criminal são permitidos, sem prejuízo dos já previstos em lei, os seguintes procedimentos de investigação e formação de provas:

[...] 
V infiltração por agentes de polícia ou de inteligência, em tarefas de investigação, constituída pelos órgãos especializados pertinentes, mediante circunstanciada autorização judicial.

A Organização das Nações Unidas observando a crescente necessidade de positivar o tema e visando intensificar o repúdio e a prevenção das infrações graves - como o tráfico de entorpecentes e pessoas - diversificou ao aceitar como meio probatório, as informações obtidas através de agente infiltrado. Segundo assevera Sousa (2015, p. 34):

Não obstante ao conhecimento de outras frentes de combate à criminalidade organizada, já em meados do século $X X$, este trabalho adotou como marco, em termos de regulação das chamadas novas técnicas investigativas, a Convenção das Nações Unidas Contra o Crime Organizado Transnacional - Convenção de Palermo.

Neste documento, ganhara destaque a nível mundial a possibilidade de infiltração de autoridade competente no ambiente criminoso com o propósito investigativo. Especificamente, no artigo 20 que trata sobre as Técnicas Especiais de Investigação, a Convenção de Palermo explicita:

1. Se os princípios fundamentais do seu ordenamento jurídico nacional o permitirem, cada Estado Parte, tendo em conta as suas possibilidades e em conformidade com as condições prescritas no seu direito interno, adotará as medidas necessárias para permitir o recurso apropriado a entregas vigiadas e, quando o considere adequado, o recurso a outras técnicas especiais de investigação, como a vigilância eletrônica ou outras formas de vigilância e as operações de infiltração, por parte das autoridades competentes no seu território, a fim de combater eficazmente a criminalidade organizada.

Atualmente, a Lei do Crime Organizado (12.850/2.013) continua prevendo tal meio de prova, como anteriormente já elencava sua precursora, porém foram feitos ajustes, que restringiram os habilitados ao exercício do labor em questão.

Basicamente, a diferenciação se deu pela extinção da competência dos agentes da inteligência e pelo preestabelecimento dos "órgãos especializados" para a constituição da sobredita operação investigatória, quais sejam: o Ministério Público e o Delegado de Polícia.

\section{O AGENTE INFILTRADO}

Antes de adentrar aos critérios para a designação do agente infiltrado, necessário se faz dirimir ponto nebuloso. Não há que se confundir agente infiltrado com agente provocador, tendo em vista o último ser o responsável pelo crime preparado, o que configura crime impossível, posto que se elabora um cenário para que o "acusado" desenvolva a conduta criminosa, sem o qual, não haveria a ação.

Valendo-se de analogia simplista, o agente provocador se porta como diretor de uma cena, preparando todo o roteiro e o ambiente, sem os quais não haveria a possibilidade do desenrolar dos fatos. Entretanto, similarmente ao agente infiltrado tem-se um ator que atua de acordo com o que lhe propõe o roteirista, no caso, o chefe da organização criminosa. Enfim, o primeiro constrói tudo que o circunda, já o derradeiro age conforme lhe é imposto pelo seu superior hierárquico, cabendo acrescentar, que a decisão sobre "intervir ou não", como já descrito, virá do Promotor de Justiça ou da autoridade policial. 
Após breve distinção, no teor do "caput" do artigo 10 da supracitada Lei de Crimes Organizados, quanto ao agente infiltrado, só terá ele permissão para atuar, se houver o aval da lei e a autorização judicial. Além disto, parafraseando o artigo seguinte, tem-se que não deve haver outra alternativa de investigação senão a reiterada, ou seja, deve estar demonstrada a necessidade da medida.

Em se tratando do indivíduo que assumirá tal função, cabe ressaltar que será um agente público investido na Polícia Civil ou Federal com atribuição investigativa. Masson (2016, p. 281) explica:

Como somente será admitida a infiltração se houver indícios do crime de organização criminosa (art. 10, § 2.․ , da LCO), entendemos que apenas os agentes policiais incumbidos de investigar esse delito poderão agir como infiltrados, ou seja, tão somente os integrantes da Polícia Federal (art. 144,

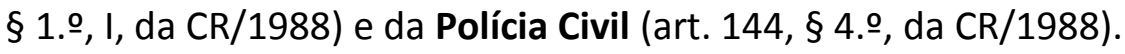

Outro fato que não poderá gerar equívoco, diz respeito à Agência Brasileira de Inteligência e ao trivialmente conhecido, P2 da Polícia Militar. Fundamentado no entendimento de Sousa (2015, p. 42-43), aquele cuidará de assuntos relacionados à soberania nacional e este não abordará questões específicas, restando apenas mapear zonas de risco e onde se faz necessário intervir. Resumindo, a inteligência da Polícia Militar é responsável por assuntos genéricos.

Findando, por ser exceção, a infiltração policial, além da autorização judicial, deverá ser precedida de planejamento detalhado da ação, onde constará todo o permitido, o prazo do trabalho, que de acordo com Masson (2016, p. 282) "será autorizada pelo prazo de até 6 (seis) meses, sem prejuízo de eventuais renovações, desde que comprovada sua necessidade", o local e, se possível, o nome ou apelido dos investigados.

Ademais, o policial deverá passar por treinamento adequado às peculiaridades da "nova" função.

\section{PUNIÇÕES PELO COMETIMENTO DE ILÍCITOS}

É razoável o questionamento frente ao instituto da infiltração policial de como seriam abordados os eventuais ilícitos cometidos na decorrência deste trabalho, pois é, absolutamente possível, que diante das circunstâncias a que estará exposto, o policial, até mesmo para angariar a confiança de seus "comparsas", cometa crimes. Se fizer de modo contrário, estará expondo a operação e por consequência, correndo risco de vida.

A legislação objetivando elucidar o assunto preceitua que aquilo que for estritamente necessário, ou seja, que não houver outro maneira de superar, será perdoado, similarmente ao que ocorre na modalidade de excludente de ilicitude supralegal nomeada "Inexigibilidade de conduta diversa". Há que se ponderar o quão complexo será se enquadrar na respectiva previsão, posto que na urgência, ter o discernimento para medir suas reações adequando-as ao permitido, não será tarefa fácil, valendo ainda apontar que, a ação do sujeito "a posteriori" será avaliada pelos gestores, demonstrando assim, outro ponto a ser considerado na concretização do instituto.

Além dos cuidados supracitados, outra opção para aquele que figurará como criminoso não ser criminalmente responsabilizado, será policiar suas ações através do Princípio da Proporcionalidade. Assim, quando existir mais de um direito na eminência de supressão, deverá o sujeito preferir o que possui maior valor social. Portanto, não será proporcional ceifar uma vida para efetivar a "participação" numa organização criminosa, por exemplo. Nas palavras de Masson (2016, p. 297):

O principal para que não ocorra essa atuação excessivamente desproporcional em relação à finalidade da investigação, permitindo-se que a operação se desenvolva de forma juridicamente adequada, a nosso 
sentir, é que em cada caso sejam estritamente observados pelo policial infiltrado os já mencionados limites espacial, temporal e investigatórios impostos na autorização judicial em consonância com as informações apresentadas ao magistrado por meio do plano operacional da infiltração.

\section{UTILIZAÇÃO VERSUS GARANTIAS INDIVIDUAIS}

A utilização de sujeito como observador e informante do Estado situado dentre os verdadeiros criminosos traz a baila reflexões quanto aos direitos de ambas as partes que compõem o procedimento. A exposição demasiada do funcionário público ao perigo e o meio probatório invasivo visualizados "a priori" questionariam a constitucionalidade do instituto.

Por cuidar apenas de fragmentos no mundo dos ilícitos, a legislação penal e quem a interpreta devem ser cautelosos em seus posicionamentos. Afinal, baseado nos princípios jurídicos, a interpretação extensiva somente se aplica para beneficiar o réu. O próprio Princípio da Legalidade disciplina por meio de seu significado bilateral que o agente público só poderá agir com fundamento legal e, por outro lado, os populares estão autorizados a fazer aquilo que o ordenamento não proíbe.

Sendo assim, a admissão da vertente de prova discutida se deu através da ratificação de legislação internacional, saldando eventuais dúvidas quanto à sua legalidade com o advento da Lei 12.850/2.013, grande avanço, pois por ser norma incriminadora, tudo aquilo que não está taxativamente previsto em lei, não poderá ser exigido, afinal, o Direito Penal tem como um de seus escopos, a restrição do direito de punir do Estado, logo, se não está na lei, não está no mundo. O inverso também é verdadeiro: se previsto em lei, poderá ser cobrado.

Quanto ao argumento de desrespeito dos direitos dos criminosos, principalmente no que concerne à intimidade e ao direito de não produzir prova contra si mesmo, ressalta-se o que os doutrinadores nomearam de prova imoral, pois o indivíduo mesmo sem sua concordância, passa a se incriminar. Ademais, poderia tomar emprestado o "corpo" da norma relativa à prova ilícita para contestar o presente modo investigatório, citando "a teoria dos frutos da árvore envenenada".

Como justificativa tem-se a esperada supremacia do Direito Público, sempre em posição soberana se comparado ao Direito Privado, isto se dá pela relevância do interesse público sobre o particular. No caso em tela, parte-se da mesma premissa. Se comprovada a existência de situação, que dependendo da consequência, beneficiará o coletivo prejudicando o individual e vice-versa, dar-se-á preferencia pela ação que resguardará o todo.

Portanto, quando direitos individuais são suprimidos, como na infiltração policial, buscando preservar outras garantias, como o bem-estar social, a paz, a prevenção de graves ilícitos e a ordem jurídica, não haverá inconstitucionalidade se em análise restar comprovado que determinado direito se sobressai entre seus pares.

\section{CONCLUSÃO}

Por todo o exposto, evidencia-se que a infiltração policial não angariou espaço na fase de investigação, por todas as incertezas que a permeiam, tanto no que se refere aos perigos da exposição do agente público à convivência com infratores especializados, quanto ao paradoxo existente entre a busca pela preservação de determinados direitos coletivos prejudicando o gozo pleno dos direitos individuais.

Além disto, a infinidade de adversidades que a execução do instituto poderá gerar ao Estado, também colabora com a inibição de seu uso.

Concluindo, para validar o instituto processual penal em questão, talvez a alternativa seja reformular a lei que o abrange, de modo a extinguir as incertezas existentes, retirando a sensação de insegurança jurídica. 


\section{REFERÊNCIAS}

ANDREUCCI, R. A. Infiltração policial: possibilidade. Carta Forense, São Paulo, set. 2013. Disponível em: <http://www.cartaforense.com.br/conteudo/artigos/infiltracao-policial-possibilidade/11950>. Acesso em: 15 ago. 2016.

BRASIL, Decreto no 5.015, de 12 de março de 2004 . Disponível em: <http://www.planalto.gov.br/ccivil_03/_Ato2004- 2006/2004/Decreto/D5015.htm>. Acesso em: 17 ago. 2016.

CAPEZ, F. Curso de direito penal: legislação penal especial. 10. ed. São Paulo: Saraiva, 2015.

MASSON, C. et al. Crime organizado. 2. ed. São Paulo: Método, 2016.

OLIVEIRA, A. M. E. M. et al. Normas e padrões para trabalhos acadêmicos e científicos da Unoeste. 3. ed. eletrônica. Presidente Prudente: Unoeste - Universidade do Oeste Paulista, 2015.

SOUSA, M. Crime organizado e infiltração policial: parâmetros para a validação da prova colhida no combate às organizações criminosas. 1. ed. São Paulo: Atlas, 2015. 